\title{
EXPERIENCE IN THE FIELD OF SUSTAINABILITY ENHANCED CONSTRUCTION CLASSIFICATION SYSTEM
}

\author{
RODRIGO LIMA, FILIPA SALVADO, MARIA JOÃO FALCÃO SILVA \& PAULA COUTO \\ National Laboratory of Civil Engineering (LNEC), Portugal
}

\begin{abstract}
Currently, due to the increasing complexity of new buildings and the urgency to promote their economic sustainability, the Architecture, Engineering, Construction and Operation (AECO) sector faces the challenge of managing all the necessary information to fulfil its basic requirements. For this information management (e.g. control, organization, structuring, storage), the importance of using standardized construction information classification systems (CICS) is emphasized. In parallel, the use of Building Information Modelling (BIM) methodology is increasingly essential. In addition, there is a global challenge to rationalize the use of natural resources in line with the United Nations (UN) Sustainable Development Goals. As the AECO sector is one of the most demanding in terms of the use of these resources, there is an urgent need to develop production models that involve the sharing, reuse, repair, renovation and recycling of existing materials and products, thus extending their life cycle. The Sustainability Enhanced Construction Classification System (SECClasS) Project presents a solution that unifies these challenges. It proposes to develop and implement a CICS optimized for sustainability, based on the principles of Circular Economy, aiming to reduce construction and demolition waste (CDW), through the use of digital tools that help and promote the careful selection and management of products with less environmental impact. This paper describes the assumptions for the development of a Portuguese CICS (in accordance with SECClasS Project), that adapts classification systems already established at an international level, such as: (i) UniClass2015 (United Kingdom); (ii) OmniClass (North America); (iii) CCS (Denmark); (iv) CoClass (Sweden); and (v) CCI (Estonia, Czech Republic, Norway, Denmark, Sweden and Finland). International standards, such as ISO 12006 and ISO 81346, as well as the Action Plan for the Circular Economy defined by the European Union in 2020 are also analysed. This research work aims to obtain a CICS that streamline decision-making processes in AECO sector, reducing negative environment impacts and promoting sustainability.
\end{abstract}

Keywords: classification systems, building information modelling (BIM), standardization, sustainability, circular economy.

\section{INTRODUCTION}

In the context of construction design and planning, the building information modelling (BIM) methodology has imposed new challenges in the Architecture, Engineering, Construction and Operation (AECO) sector. Project information, previously transmitted through graphic elements, in two dimensions, and with instructions in text form, is now transmitted through three-dimensional models, containing data that allows several virtual simulations such as: buildings behavior, quantities, environmental impacts, costs or deadlines.

The use of smart objects in three-dimensional BIM models is capable to support different simulations that increase the predictability and reduce the risks of construction projects. The information contained in these objects causes a large data increase, requiring tools to assist in its management.

The Construction Information Classification Systems (CICS) have been developed in this context. While they were previously useful for processing, organizing and retrieving information, with the new technology they are now fundamental for managing the large volume of data. The integrated way of sharing this information is also a BIM benefit, and this sharing relies on the CICS to improve communication between those involved in the construction and operation processes, in order to ensure a uniform language throughout the 
building's life cycle, standardizing it through codes recognized by human actors or by machines [1].

To overcome these challenges, the Sustainability Enhanced Construction Classification System (SECClasS) Project aims to present a solution that meets the needs and peculiarities of the Portuguese AECO sector, proposing a Portuguese Construction Information Classification System optimized for sustainability, based on the principles of Circular Economy and on international experiences in developing their own systems and adapting them to the several works and materials types used in Portuguese AECO sector.

This paper aims to analyze the main existing CICS and to expose their most relevant concepts. It also intends to present the important concepts that can be a basis for the Portuguese CICS standardized structure, as well as the concepts used by European legislation and normalization for a circular economy. Finally, the paper proposes the choice of one of the international systems as a basis to develop the Portuguese CICS.

\section{CONCEPTS, USE AND STANDARDIZATION OF CICS}

Classification is defined as the grouping of a set of items into classes, categories or groups that have common characteristics, based on pre-established rules and according to the purpose of a process. In general, classification is done with the objective of finding the best possible order. So, after classifying an element, it is easier to find it within a given set. Although there is no absolute way to classify, the most correct would be that all trading partners use a common language to group elements [2].

There are several types of classification that can be described, and that are associated, depending on the objectives, the scope and the particularities of the system to be developed. Classifications can be divided into: (i) specialized, when it is intended to focus on a particular subject; (ii) general, when it is intended to cover a universe of information; (iii) enumerative, when it is sought to list all subclasses, including compound ones, that relate to the main class; (iv) hierarchical, when subclasses are created from a simple and particular principle of division of the main class and compound classes are defined by association of the subclasses; (v) documental, when the main objective is the classification of documents or other types of information in order to facilitate their organization, location and storage; and (vi) analytical (taxonomy or scientific), when it is intended to systematize information and provide a basis for its explanation and understanding [1].

CICS emerged in the twentieth century in order to meet the sector's needs, to organize itself in a rational manner, to facilitate storage and retrieval of information, and to exchange information that is relevant to the sector. In Europe, the United Kingdom developed the CESMM system, in 1976, by the ICE (Institution of Civil Engineers), geared to the detailed survey of civil engineering works quantities. Its great applicability to civil engineering works led it to be updated three times, with the last version (CESMM3) published in 1992 [2].

A CICS is configured in a set of interdependent elements that form an organized whole. Such systems can be developed according to the needs of each country, region or even a company, in order to meet their desires in organizing themselves, and can follow international classification standards [1]. The classification and harmonization of information through those systems have the main objective of making collaborative work more effective, even when performed at a distance or in different formats, to ensure consistency and comparability, and to enable the construction process stakeholders to be less dependent on the weaknesses of others [2]. 


\subsection{ISO 12006}

ISO has produced standards to organize the classification and exchange of information, such as ISO 12006-2 and ISO 12006-3, whose major objective is to guide the structuring of construction classification systems. The base structure proposed by ISO aims to provide the systems in development with the necessary scope to respond to the growing size and complexity of construction works. Indeed, a classification system designed in accordance with ISO 12006-2 should cover the entire life cycle of the construction project, with a wide variety of construction works [1].

However, there is no specific and closed recommendation on the structuring model to be adopted for each situation, which allows the user to choose the one that best suits the system he want to make the classification. The standard still has another role in the development of classification systems. Due to the existence of several CICS, the information exchange between them tends to be facilitated if they are developed in accordance with the proposed guidelines. Based on this function, ISO 12006-2 recommends tables, which can be used in combination or separately according to the user's needs [3].

\subsection{ISO/IEC 81346}

The latest series of ISO/IEC 81346 constitute the standards for the components identification belonging to any technical system. These standards deal with technical systems in the broadest sense of the word, including construction (structures and technical installations), industrial systems, as well as machinery in general and, moreover, are of considerable importance for the base documentation of the machinery and equipment European Directive. This documentation links the marking of components and associated documentation [4].

The systems based on ISO/IEC 81346 series are structured differently from the ones based on ISO 12006-2. They have a smaller group of Functional Systems, Technical Systems and Components (items corresponding approximately to the Elements, Systems and Products tables of ISO12006-2 based systems), and differentiates them by assigning different properties (for example, a port is always designated as a port, but subtypes are defined by their properties), which is reflected in the designation or classification. Additional notations are attached to the initial/root notation, as the item is progressively defined throughout the design and documentation process. This results in a stable and recognizable designation throughout the project life [5].

ISO/IEC 81346 is divided into four parts: (i) Part 1: Basic rules (IEC 81346-1); (ii) Part 2: Classification of objects and codes for classes (IEC 81346-2); (iii) Part 10: Power plants (ISO/TS 81346-10) and Power supply systems (ISO/DIS 81346-10); and (iv) Part 12: Construction works (ISO 81346-12). Parts 1 and 2 also have rules for the creation of unambiguous identifiers that define, through the Reference Designation System (RDS), a combination of well-defined relationships (part and type of relationships) and different aspects (function, product, location and type) [6].

\section{CICS AND THE BIM METHODOLOGY}

Based on the BIM concepts and objectives, recent CICS have been developed and adapted to this methodology. The purpose is to manage all the information produced in the process that, through smart objects, is based on a three-dimensional virtual representation of the construction project, where the information is integrated, relating to its entire life cycle, so that its results and tools bring advantages to the AECO sector, such as the entire process transparency [1]. 
The information is introduced in BIM models through the smart objects. Those objects are responsible for integrating valuable information about production processes, communication and analysis of digital three-dimensional models, assuming then particular importance in the creation and development of models that allow to represent virtually, in an equivalent way, the real products. In fact, the correct insertion of information in the object is fundamental for the best use of BIM methodology. For this, there is the need to adopt methods and strategies that enable the correct definition and implementation of these elements. This is the case of the CICS, which guide and organize the way of information is made available in smart objects [1]. Fig. 1 shows the types of data, in a smart object, using BIM.

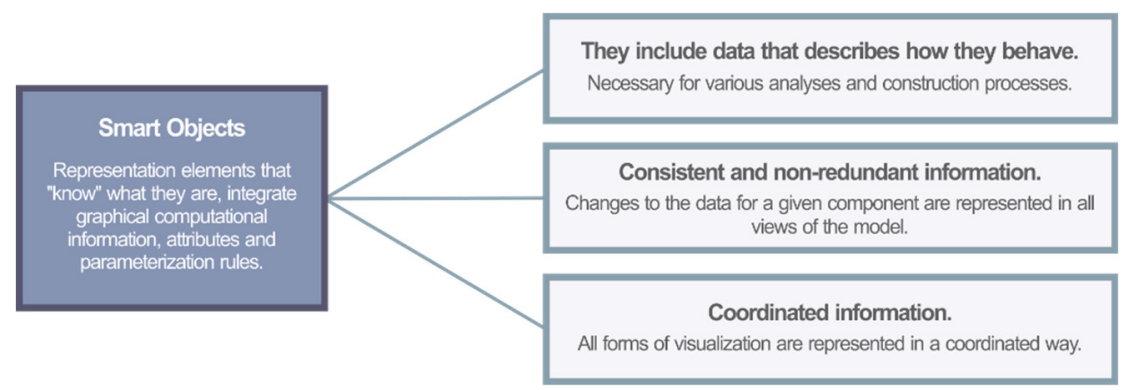

Figure 1: BIM object data [7].

BIM encompasses information about developments during their entire life cycle, at the design, planning, construction and operation phases. The classification and structuring of information thus enables the integration between the different stages and designs of the construction system, reducing errors and optimizing the process. The technology on which BIM is based allows the generated model to contain precise and detailed information about the geometry, as well as a set of data regarding the construction procedures, the technologies used and the procurement process, necessary to realize the project [8]. This presupposes a complete change in the flow of information exchanged among the stakeholders, relative to the traditional workflow, that becomes centralized in the BIM model avoiding the eventual loss of information, as shown in Fig. 2. Thus, CICS become indispensable as an information management tools.
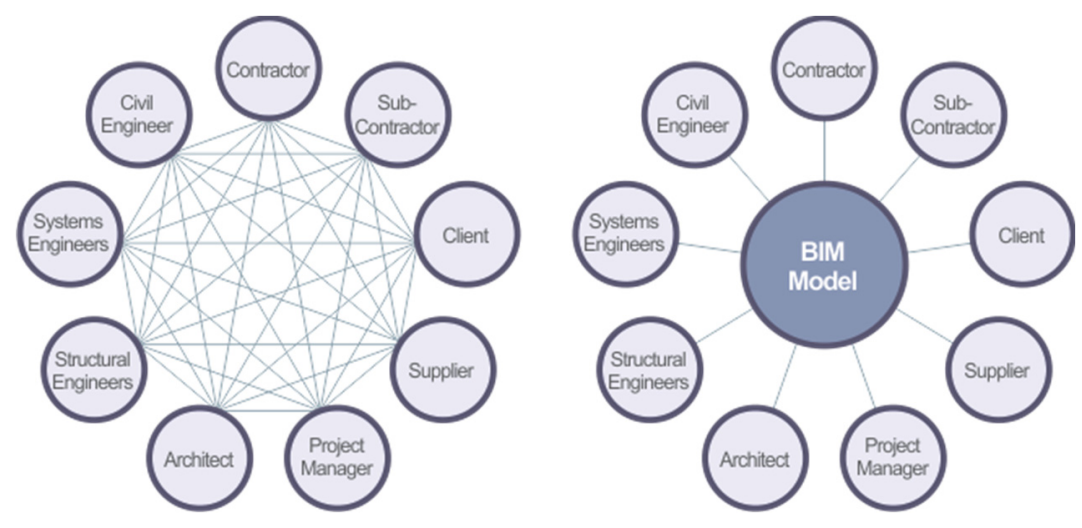

Figure 2: Traditional vs. BIM workflow [9]. 


\section{INTERNATIONAL CLASSIFICATION SYSTEMS}

Considering the analysis of CICS used in Europe and wide world, the development of the present paper is based on a study conducted by the Faculty of Civil Engineering of the Czech Technical University in Prague, Czech Republic, in association with the Czech Agency for Standardization (PS03). This research includes 18 international CICS, that through preestablished criteria were evaluated: (i) horizontal details, dealing with more complex classifications and referring to the scope of CICS; (ii) vertical details, consisting on checking the basic classifications suggested by means of ISO 12006-2 tables; (iii) chronological details, concerning the classification of the phases of a construction project and the state of the structures; (iv) the main properties, comprising ontological, functional and license; and (v) compliance with other systems, regarding compatibility with BREEAM, LEED, etc., certification systems and with BIM software (e.g. Revit, ArchiCAD, Tekla).

An "ideal construction information classification system" was created that can be used as a basis for comparison between the selected CICS. The different characteristics of the systems do not allow such a direct comparison between them, so the method is adopted to avoid a distortion of the final results.

The overall results are presented in Table 1, with the respective scores obtained by each CICS. The values presented indicate how close the best rated are to the CICS imaginary ideal, as defined based on approved criteria and weights for each aspect. The table is ranked by ranking from the best CICS to the worst.

Table 1: Comparison results. (Source: Adapted from Faculty of Civil Engineering at the University.)

\begin{tabular}{|l|c|c|c|}
\hline General classification & Range & Average & Classification \\
\hline CICS & $80-90 \%$ & $84.85 \%$ & 1 \\
\hline Coclass & $66-82 \%$ & $74.08 \%$ & 2 \\
\hline UniClass 2015 & $67-77 \%$ & $72.01 \%$ & 3 \\
\hline TFM a NS6451 & $59-70 \%$ & $64.30 \%$ & 4 \\
\hline CI/SfB & $52-75 \%$ & $63.49 \%$ & 5 \\
\hline KKS & $48-74 \%$ & $61.24 \%$ & 6 \\
\hline TALO 2000 & $53-69 \%$ & $60.90 \%$ & 7 \\
\hline OmniClass & $53-68 \%$ & $60.49 \%$ & 8 \\
\hline Natspec Worksection & $45-57 \%$ & $52.05 \%$ & 9 \\
\hline Uniformat and Masterformat & $42-62 \%$ & $52.00 \%$ & 10 \\
\hline SKP & $39-56 \%$ & $47.65 \%$ & 11 \\
\hline SNIM & $44-51 \%$ & $47.43 \%$ & 12 \\
\hline TSKP & $45-49 \%$ & $46.99 \%$ & 13 \\
\hline ASA QS Elemental Class & $37-54 \%$ & $45.28 \%$ & 14 \\
\hline RTS BIM & $30-57 \%$ & $43.69 \%$ & 15 \\
\hline CZ-CC & $32-53 \%$ & $42.75 \%$ & 16 \\
\hline BIM7AA & $34-48 \%$ & $41.12 \%$ & 17 \\
\hline KSO (JKSO) & $24 \%$ & $23.83 \%$ & 18 \\
\hline
\end{tabular}


In the study conducted by the Czech researchers, UniClass2015 (United Kingdom), CoClass (Sweden) and CCS (Denmark) systems are the best evaluated.

In addition, it was defined that, because they are globally consolidated CICS, OmniClass (North America) and CCI (a system under development by several northern European countries) would also be included in the analyses carried out by the present research.

Besides the Czech study, the SECClasS Project takes into consideration aspects that are fundamental for the Portuguese AECO sector and that aim to facilitate the implementation and diffusion of the system in Portugal. Specific decision-making information for the choice of a new base system was analyzed: (i) basic information; (ii) structure, tables and compliance with ISO 12006-2 and ISO/IEC 81346; (iii) designation of reference codes; (iv) license and language of the system documentation; (v) Updates and expandability of the system; (vi) sustainability component; (vii) digitization of the system and interconnection with modelling software.

\subsection{UniClass2015}

The CICS developed by the United Kingdom, the UniClass2015, under the responsibility of Nation Building Specification (NBS) has great advantages. Its structure based on the concepts of ISO 12006-2, is wide, hierarchical and its tables make relationships with each other. The complement of its terminology and coding database is flexible, allowing the introduction of new elements. The system is adapted to the constructive process of the European market, facilitating adaptation to the Portuguese AECO sector. Its updates are systematic, and documentation is available in English. NBS also provides tools that enable interconnection with BIM modeling software. In addition, the SECClasS Project was authorized by NBS to translate and use UniClass2015 as the basic system for a Portuguese CICS.

\subsection{CoClass}

CoClass was created in Sweden between 2017 and 2018 in response to the digitization of the construction industry and its connection to BIM. This is a complex CICS, and its use is mainly linked to the country of origin [10]. CoClass is structured differently from the "classic CICS" therefore brings differences with respect to UniClass2015 and OmniClass. Its general structure is based on ISO 12006-2 but uses ISO 81346 series for classifications of functional systems, techniques systems, elements, and spaces. The CICS proposes to have a humanreadable digital language and machines using the RDS coding system, proposed in ISO 81346 , to codify references to products. CoClass has some disadvantages: the documentation is partially available in English and most in Swedish, and CICS is not fully open source, having cost of use, providing only basic tools and classifications for free. Its updates are systematic and allow development and insertion of new classifications. The system considered the state of the structures. When analysing the Property table, information is found regarding durability, mechanical durability, object state or year of reconstruction, according to real estate registration data. Due to limited access to the system, no further information can be verified.

\section{$4.3 \mathrm{CCS}$}

Cuneco Classification System (CCS) originates in Denmark, under the responsibility of Molio - Construction Information Centre, BuildingSmart's Danish partner. The development started in 2010, using ISO 81346 series, in the 2009 version. The purpose of the system is to 
ensure that digital data can be clearly exchanged between production chains, phases and software's, thereby helping to increase construction productivity. Provide a unique identity for each part of the building and be able to be applied to all parts of the building, from design to operation, so that all parties using the same concepts can be based on each other's information and classify the information. The documentation is in Danish, limited to a part of it and tables translated into English. CICS is available in the basic version free of charge but requires annual subscription for full use of resources. CCS provides tools for sorting objects, along with a system for defining codes and definitions that can be accessed using the CCS Navigate tool. The connection with the modelling software, Revit and ArchiCAD, is made using plug-ins [10]. No sustainability classifications were found.

\subsection{OmniClass}

OmniClass is a CICS developed by CSI (Construction Specification Institute), CSC (Construction Specification of Canada) and AIA (American Institute of Architects), developed to serve the AECO sector of those countries. It is considered a traditional system, as UniClass2015, which has its structure based on ISO 12006-2. The biggest difference between them is the construction process in which they use as a base, with OmniClass being adapted to the processes of the North American construction sector, but still compatible with other international systems. This CICS is an open source standard to any person or organization, promoting the exchange of information between stakeholders. The development and update have the participation of the industry, but is verified an outage, being the last occurred in 2019. The system has good connection with BIM modeling software, documentation in English and, although the study of the Czech Agency for Standardization affirm that the license terms allow editing and distribution, the information could not be verified about the commercial use. A great advantage of OmniClass, to the SECClasS Project, is the property table, capable to classify information associated with sustainability.

\subsection{CCI}

The origin of the development of the Construction Classification International (CCI) arises from Estonia's need to develop its own CICS that would serve that country. Soon other neighbouring nations would feel the same need and together the Czech Republic, Finland, Norway, Denmark, Sweden join Estonia for this goal. The CCI working group then decides to use CoClass and CCS as the basis for the new international CICS, believing that the implementation of a common a cross-border classification system improves cooperation, increases standardization, and improves digital working methods. As a result, the CCI core is the common element between ISO, CCS and CoClass standards [11]. The system uses ISO 12006-2 in its general structure and the ISO 81346 series for systems and components. The system aims to be developed in English with possible translations into the languages of the countries that are part of the project. According to the letter of intent signed by the developers, CICS must be free of cost, but a formal use license document as well as upgrade protocols is not available yet. The sustainability component also cannot be evaluated because of the development stage.

\section{CONCLUSIONS}

The BIM methodology, admittedly, brings advantages to the AECO sector. The applications generate a large amount of information needed to provide designers an increasing number of possibilities for simulation and operationalization of assets. CICS becomes an essential tool, 
but not the only one, in the management of this information. Therefore, and with the demand for a CICS that meets the needs of the Portuguese market, the SECClasS Project seeks to develop a system based on European and North American experiences that also adds an unexplored component in existing CICS: sustainability.

The study carried out by researchers from the Faculty of Civil Engineering of the Czech Technical University in Prague, in association with the Czech Agency for Standardization, was analysed in this paper and the conclusions were compared with the objectives of the SECClasS Project presenting the following results:

1. None of classification system is perfect, as the requests of each user group are distinct. The flexibility and adaptability of the system is essential, as each country will always have its own classification needs;

2. The CICS's purpose must be in accordance with the BIM methodology and able to increase the sustainability and circular economy, responding to current uses, but also to future uses;

3. Systems that are hyper-adapted to a specific type of construction or a life cycle phase should be avoided;

4. Correspondence with other systems is essential, so they must be in accordance with international standards, in this case ISO 12006-2;

5. More complexes CICS have greater breadth of future application and development. However, the level of complexity should always be evaluated, so as not to derail human interaction and perception;

6. The oldest CICS have advantages such as greater consolidation in the market, acceptance by professionals and the language availability;

7. The CICS's future maintenance, including, but not limited to its expansion, updating and maintenance, are factors to consider, and it is important to define a clear methodology, including and defining responsible and resources;

8. The license to use and adapt, the current dynamism of the entity(s) holder of the rights in the expansion, correction and improvement and responsiveness to external contributions should be investigated and considered in decision-making for a basic CICS.

Based on the reasons presented, the existence of an open license and the authorization for its translation and adaptation, the degree of dissemination and implementation in object libraries, the choice for the base system for the SECClasS Project falls on the UniClass2015 system, managed by NBS. The next steps are: firstly, establish a methodology for adapting and translating the system into the Portuguese language and reality; secondly, establish how to include the sustainability component. Finally, it is of the utmost importance to engage the technical environment, collecting and incorporating their feedback.

\section{ACKNOWLEDGEMENTS}

The implementation of BIM in Portugal is a reality and professionals demand for a Portuguese Classification System that facilitates the processing, communication and sharing of information and models that maintains standard communication between all agents involved and throughout the construction life cycle.

SECClasS is a project funded by The EEA Grants with the purpose of developing a Construction Information Classification System for Portugal, with a component focused on sustainability, supporting decision-making that encourages reuse, recycling, durable products, possibility of relocation of structures and minimal waste. 
The project aims to facilitate the Circular Economy in Construction by introducing a CICS optimized for sustainability, oriented to the BIM methodology and that will serve not only the sustainability component, but also the other BIM uses. It will also allow unifying terminology at all scales, facilitating communication, selection of materials and components, as well as an accurate assessment of the impacts of buildings throughout their life cycle.

With the development of the SECClasS Project, it is expected to achieve the following results: (i) Portuguese classification system that will allow more advanced BIM uses based on traditional systems with sustainability component: environmental impacts, reuse, recycling; (ii) Manual and Library of BIM Objects, with traditional and sustainability components; and (iii) Online platform with artificial intelligence tools that learns from users.

\section{REFERENCES}

[1] Nunes, H.M., Sistema de Classificação de Informação da Construção - Proposta de metodologia orientada para objetos BIM. Dissertação de mestrado, Departamento de Engenharia Civil, FCT: Lisbon, Portugal, 2016.

[2] Pereira, R.M.S., Sistemas de Classificação na Construção. Síntese comparada de métodos. Dissertação de mestrado, Departamento de Engenharia Civil, Faculdade de Engenharia da Universidade do Porto: Porto, Portugal, 2013.

[3] Lima, R.T. et al., Sistemas de Classificação da Informação da Construção Comparação entre as realidades portuguesa e brasileira. Relatório do Projeto P2I, LNEC: Lisbon, Portugal, 2019.

[4] Balslev, H., DS Handbook 166:2010 - A Guide to Reference - Preparation of TAG Numbers, Letters Codes, and Interfaces Between Systems. Danish Standards Foundation: Charlottenlund, Denmark, 2010.

[5] Friborg, G., ICIS PROJECT \#3: Classification, Identification and BIM. ICIS International Construction Information Society: Zurich, Switzerland, 2017.

[6] Balslev, H., The Reference Designation System (RDS): A common naming convention for systems and their elements. 26th Annual INCOSE International Symposium (IS 2016), Edinburgh, 2016.

[7] The NBS, What is Uniclass 2015? https://www.thenbs.com/knowledge/what-isuniclass-2015 Accessed on: 17 Mar. 2021.

[8] Eastman, C. et al., BIM Handbook: A Guide to Building Information Modelling for Owners, Managers, Designers, Engineers and Contractors, New Jersey, 2008.

[9] ARC BIM, BIM: What is it and how does it affect me?, 2012

[10] Agência Checa para a Normalização, Pesquisa e Comparação dos Sistemas de Classificação dos Elementos de Construção no Contexto do Building Information Modeling (BIM) - Análise de sistemas de classificação selecionados para efeitos da Norma de Dados Checa. Universidade Técnica Checa em Praga, Faculdade de Engenharia Civil: Prague, Czech Republic, 2018.

[11] Saar, J., CCI International - Presentation of Estonia Government Agenda. Ministry of Economic Affairs and Comunications. Estónia, 2019.

[12] CSI, OmniClass: Introduction and User's Guide., p. 29, 2006.

http://www.omniclass.org/tables/OmniClass_Main_Intro_2006-03-28.pdf. Accessed on: 19 Mar. 2021.

[13] ISO 12006-2:2015 - Building construction - Organization of information about construction works - Part 2: Framework for classification. http://visnormas.lnec.pt/ php/menu.php.html. Accessed on: 8 Mar. 2021.

[14] CSI, 2020. OmniClass. https://www.csiresources.org/standards/omniclass. Accessed on: 19 Mar. 2021. 
24 Building Information Modelling (BIM) in Design, Construction and Operations IV

[15] Svensk Byggtjänst (Swedish Building Centre), CoClass Website. https://coclass.byggtjanst.se/. Accessed on: 24 Mar. 2021.

[16] Molio Construction Information Centre, CCS: Cuneco Classification System Website. https://molio.dk/produkter/digitale-vaerktojer/gratis-vaerktojer/ccs-cunecoclassificationsystem. 